Asad Khan, MD

Department of Internal Medicine, Cleveland

Clinic, Cleveland, $\mathrm{OH}$; Clinical Instructor

Cleveland Clinic Lerner College of Medicine

of Case Western Reserve University,

Cleveland, $\mathrm{OH}$
Erik H. Van Iterson, PhD

Director, Cardiac Rehabilitation,

Section of Preventive Cardiology

and Rehabilitation, Heart, Vascular

and Thoracic Institute, Cleveland Clinic

Cleveland, $\mathrm{OH}$
Luke J. Laffin, MD

Co-director, Center for Blood Pressure

Disorders, Section of Preventive Cardiology

and Rehabilitation, Heart, Vascular.

and Thoracic Institute, Cleveland Clinic,

Cleveland, $\mathrm{OH}$

\title{
The obesity paradox in heart failure: What is the role of cardiorespiratory fitness?
}

\section{ABSTRACT}

The obesity paradox describes a survival benefit for higher body mass index in patients with heart failure. But other factors like cardiorespiratory fitness may play a role in heart failure development, severity, and survival. Although more research is needed to better understand the relationships between body mass index and fitness in patients with heart failure, evidence indicates that recommending weight loss and an exercise program is appropriate for most patients.

\section{KEY POINTS}

Obesity increases the risk of developing heart failure regardless of fitness level, but better fitness attenuates the risk.

Weight appears to be only part of the obesity paradox story. Evidence indicates that cardiorespiratory fitness is a major factor influencing the paradox.

Fitness modifies the obesity paradox in patients with heart failure and reduced ejection fraction, with the paradox remaining strongest in patients who are less fit.

Although more research is needed on risk reduction for heart failure, evidence indicates that intentional weight loss and increased fitness are advisable for select patients.
$\mathrm{O}$ BESITY IS A WELL-ESTABLISHED and important predictor of morbidity and mortality in patients with cardiovascular (CV) disease and other conditions, including chronic kidney disease and chronic obstructive pulmonary disease. Yet some studies report obesity is associated with lower mortality in patients with heart failure - a finding known as the obesity paradox.

Though not fully understood, several possible reasons for the obesity paradox have been proposed (Table 1). ${ }^{1-9}$

Understanding the obesity paradox has important clinical implications given the high prevalence of obesity in patients with heart failure $(42 \%$ of those with preserved ejection fraction $[\mathrm{HFpEF}]$ and $36 \%$ of those with reduced ejection fraction $[\mathrm{HFrEF}]) .{ }^{10}$ What should patients be advised about weight management? What should patients be advised about cardiorespiratory fitness, a major factor influencing the paradox?

This review summarizes current understanding of the roles of cardiorespiratory fitness and body mass index (BMI) in patients with heart failure and its development. It also discusses how to advise patients about fitness and body mass in light of the obesity paradox.

\section{BENEFIT OF FITNESS \\ IN CARDIOVASCULAR DISEASE}

The effect of cardiorespiratory fitness on CV outcomes is an active area of clinical research. The standard for measuring cardiorespiratory fitness is cardiopulmonary exercise testing, using 
TABLE 1

\section{Select theoretical mechanisms of the obesity paradox}

Greater metabolic reserves

Less cardiac cachexia

Increased concentration of tumor necrosis factor receptors

Earlier presentation owing to greater functional impairment

Attenuated response to renin-angiotensin-aldosterone system

Higher blood pressure leading to greater use of cardioprotective medications

Adapted from reference 6

an incremental treadmill or upright cycle protocol. Numerous studies have found associations between poor $\mathrm{CV}$ disease outcomes and low peak exercise oxygen uptake (peak $\left.\mathrm{VO}_{2}\right) \cdot{ }^{11,12}$

\section{Low fitness predicts poor outcomes}

In 1996, Blair et $\mathrm{al}^{13}$ were among the first to quantify the effects of cardiorespiratory fitness on cardiovascular disease outcomes. After fol-

Low fitness

is a strong independent predictor of cardiovascular disease mortality lowing 25,341 men and 7,080 women in a preventive medicine clinic for about 9 years, they found that low fitness was independently associated with increased all-cause mortality in both men (relative risk [RR] 1.52, 95\% confidence interval [CI] 1.28-1.82) and women (RR 2.10, 95\% CI 1.36-3.21). Low fitness was associated with statistically significant increased cardiovascular disease mortality risk in men (RR 1.70, 95\% CI 1.28-2.25), although the difference was not statistically significant in women. In both sexes, low fitness was a more significant prognostic factor than other traditional cardiac risk factors. Interestingly, elevated BMI (> $\left.27 \mathrm{~kg} / \mathrm{m}^{2}\right)$ was not found to be significantly associated with increased mortality in either sex.

Fitness may be more important than weight A 1999 prospective observational study by Wei et $\mathrm{al}^{14}$ also found that low cardiorespiratory fitness is a strong independent predictor of cardiovascular disease mortality in the general population, and perhaps more so than BMI. The study assessed nearly 26,000 men for cardiorespiratory fitness, cardiovascular disease, and risk factors for cardiovascular disease development, with follow-up for about 10 years. Cardiorespiratory fitness was determined using maximal treadmill exercise testing with age-based metabolic equivalent (MET) values for fitness levels. Participants also were stratified by BMI using standard thresholds for normal weight $\left(18.5-24.9 \mathrm{~kg} / \mathrm{m}^{2}\right)$, overweight $\left(25.0-29.9 \mathrm{~kg} / \mathrm{m}^{2}\right)$, and obesity $\left(>30 \mathrm{~kg} / \mathrm{m}^{2}\right) .{ }^{14}$

Results showed that cardiovascular disease mortality increased with increasing BMI levels. ${ }^{14}$ Expectedly, the lowest risk for cardiovascular disease mortality was a combination of normal weight and high fitness. However, the relative risk of cardiovascular disease mortality in the obese high-fitness cohort was half that in the lowfitness normal-weight cohort, suggesting that fitness is a more important predictor of cardiovascular disease mortality than body weight. The effect of low cardiorespiratory fitness on cardiovascular disease mortality was also higher than the presence of diabetes, dyslipidemia, hypertension, or current smoking across all BMI levels. ${ }^{14}$

\section{HEART FAILURE DEVELOPMENT: CARDIORESPIRATORY FITNESS AND BMI}

The mechanisms related to obesity that contribute to the development of HFpEF and $\mathrm{HFrEF}$ include hemodynamic alterations that may predispose the patient to changes in cardiac morphology and ventricular function. ${ }^{10}$

\section{Possible mechanisms}

The mechanisms related to low cardiorespiratory fitness that contribute to the development of heart failure are not well understood. Low cardiorespiratory fitness may indirectly affect development of cardiovascular risk factors (ie, reduced cardiorespiratory fitness is associated with a low level of physical activity), ${ }^{15}$ which may accelerate the development of heart failure risk factors including diabetes, hypertension, and coronary artery disease. Alternatively, cardiovascular symptoms such as angina or dyspnea on exertion may limit habitual physical activity, in turn leading to reduced cardiorespiratory fitness.

Even in the absence of traditional cardiovascular disease risk factors, studies demonstrate that sedentary aging leads to increased stiffness of the left ventricular myocardium, a potential substrate for heart failure. ${ }^{16}$ Higher 


\section{TABLE 2}

\section{Studies assessing BMI and cardiorespiratory fitness: Effect on heart failure development}

\begin{tabular}{|c|c|c|c|c|}
\hline Study & $\mathbf{N}$ & Design $^{a}$ & End point & Main findings \\
\hline $\begin{array}{l}\text { Pandey et al }{ }^{19} \\
\text { Cooper Center } \\
\text { Longitudinal } \\
\text { Study }\end{array}$ & 19,485 & $\begin{array}{l}\text { Patients stratified by } \\
\text { BMI and peak METs } \\
\text { into quintiles }\end{array}$ & $\begin{array}{l}\text { Long-term risk } \\
\text { of hospitaliza- } \\
\text { tion for HF }\end{array}$ & $\begin{array}{l}\text { Higher midlife BMI was significantly associated with } \\
\text { greater risk of hospitalization for HF in older age. This } \\
\text { association was attenuated after adjusting for cardio- } \\
\text { respiratory fitness. }\end{array}$ \\
\hline $\begin{array}{l}\text { Kenchaiah } \\
\text { et al }{ }^{20} \\
\text { Physicians' } \\
\text { Health Study }\end{array}$ & 21,094 & $\begin{array}{l}\text { Patients stratified by } \\
\text { BMI and vigorous } \\
\text { physical activity }\end{array}$ & New onset HF & $\begin{array}{l}\text { Compared with lean participants, overweight and } \\
\text { obese participants had increased HF risk. Vigorous } \\
\text { physical activity conferred decreased HF risk. No } \\
\text { interaction was found between BMI, vigorous physical } \\
\text { activity, and HF risk. }\end{array}$ \\
\hline Hu et $\mathrm{al}^{21}$ & 59,178 & $\begin{array}{l}\text { Patients stratified by } \\
\text { physical activity and } \\
\text { indicators of adipos- } \\
\text { ity (eg, BMI, waist } \\
\text { circumference, waist- } \\
\text { to-hip ratio) }\end{array}$ & New onset HF & $\begin{array}{l}\text { Higher BMI, waist circumference, or waist-to-hip ratio } \\
\text { was associated with increased HF incidence in men } \\
\text { and women. The protective effect of physical activity } \\
\text { on HF risk was consistent in participants at all levels } \\
\text { of BMI. }\end{array}$ \\
\hline Kokkinos et al22 & 20,254 & $\begin{array}{l}\text { Patients stratified by } \\
\text { BMI and cardio- } \\
\text { respiratory fitness in } \\
\text { quartiles }\end{array}$ & New onset HF & $\begin{array}{l}\text { Increased cardiorespiratory fitness was associated } \\
\text { with progressively lower HF risk regardless of BMI. } \\
\text { After adjusting for fitness, BMI was not a significant } \\
\text { predictor of HF risk. }\end{array}$ \\
\hline $\begin{array}{l}\text { Pandey et al }{ }^{23} \\
\text { Look AHEAD } \\
\text { trial }\end{array}$ & $\begin{array}{l}5,109 \\
\text { (with } \\
\text { DM) }\end{array}$ & $\begin{array}{l}\text { Patients stratified by } \\
\text { BMI and cardio- } \\
\text { respiratory fitness into } \\
\text { tertiles }\end{array}$ & New onset HF & $\begin{array}{l}\text { High cardiorespiratory fitness was associated with } \\
\text { lower risk of developing HFpEF. Sustained long-term } \\
\text { improvement in fitness was associated with lower risk } \\
\text { of HF after } 4 \text { years. }\end{array}$ \\
\hline
\end{tabular}

${ }^{a}$ All studies are retrospective.

$\mathrm{AHEAD}=$ Action for Health in Diabetes; $\mathrm{BMI}=$ body mass index; $\mathrm{DM}=$ diabetes mellitus; $\mathrm{HF}=$ heart failure; $\mathrm{HFpEF}=$ heart failure with preserved ejection fraction; METs = metabolic equivalents

levels of physical activity are associated with beneficial effects on cardiovascular measures, including improved early diastolic filling time and favorable cardiac remodeling. ${ }^{17}$ In addition, an animal study showed a direct and favorable effect of exercise training on cardiac structure and function, leading to a delayed onset of heart failure. ${ }^{18}$

\section{Study comparing fitness and BMI}

The combined impact of cardiorespiratory fitness and BMI on heart failure development is gaining increasing attention, and many studies have been conducted (Table 2). ${ }^{19-23}$

Data from the Cooper Center Longitudinal study ${ }^{19}$ indicated that cardiorespiratory fitness may be at least as important as BMI for developing heart failure. The study stratified nearly 20,000 participants by standard BMI thresholds and cardiorespiratory fitness levels (low, moderate, and high as determined by calculated METs achieved with treadmill exercise testing). A higher BMI during midlife was associated with a significantly greater risk of heart failure hospitalization in older patients (age 65 and older), even after adjusting for other established heart failure risk factors. When adjusted for cardiorespiratory fitness, this association was attenuated, such that cardiorespiratory fitness accounted for $47 \%$ of the heart failure risk associated with BMI. Furthermore, the BMI-associated risk of hospitalization for heart failure was more pronounced in participants who had low fitness or were moderately fit. 
A subgroup of about 9,000 participants underwent repeat measurements of cardiorespiratory fitness and BMI at a median followup of 4.2 years. Increased cardiorespiratory fitness, but not BMI, was significantly associated with decreased risk of heart failure hospitalization in older patients (hazard ratio [HR] 0.91, 95\% CI 0.84-0.98 per 1 MET increase). ${ }^{19}$

Data from the Physicians' Health Study showed that participation in self-reported vigorous activity (defined as "working up a sweat") 1 to 3 times a month conferred a 26\% decrease in new-onset heart failure development. ${ }^{20}$ In contrast, a $1-\mathrm{kg} / \mathrm{m}^{2}$ increase in BMI increased the risk of heart failure by $13 \%$. Adjusting for vigorous physical activity did not alter the risk of heart failure associated with elevated BMI.

Hu et $\mathrm{al}^{21}$ studied the relationship between physical activity, heart failure risk, and indicators of adiposity (ie, BMI, waist circumference, and waist-to-hip ratio) in nearly 60,000 Finnish participants who were free of heart failure at enrollment. During a mean followup of 18.4 years, the risk of developing heart failure directly increased with BMI and other measures of adiposity for men and women. Moderate or high levels of physical activity were associated with a reduced risk of heart failure in both sexes at all levels of BMI and waist-to-hip ratio.

In a study published in 2019, Kokkinos et $\mathrm{al}^{22}$ stratified 20,000 US men by standard BMI thresholds and cardiorespiratory fitness. Fitness thresholds were based on quartiles following age and sex-specific MET adjustments. After a mean follow-up of 13.4 years, they found that heart failure risk increased progressively with decreasing fitness in each BMI category. Although age, BMI, and cardiorespiratory fitness were strong independent predictors of heart failure risk, the association between BMI and heart failure risk was no longer statistically significant after adjusting for fitness. Each increase of 1 MET was associated with a $16 \%$ lower risk of heart failure (HR 0.84; 95\% CI 0.83-0.86; P $<.001)$.

\section{Clues from patients with diabetes}

A recent post hoc analysis of the Look AHEAD (Action for Health in Diabetes) trial ${ }^{23}$ also examined the impact of fitness and BMI on heart failure development. It found that intensive life- style modification did not lower the risk of heart failure more than diabetes support and education groups (HR 0.96, 95\% CI 0.75-1.23).

However, a pooled multivariate analysis found a statistically significant, graded, inverse association between baseline cardiorespiratory fitness and heart failure incidence in participants who were moderately or highly fit. Interestingly, this association was only observed for heart failure with preserved but not reduced ejection fraction. Also, the association of BMI with heart failure was not stastistically significant after adjusting for baseline cardiorespiratory fitness and traditional risk factors. In a subset of patients who underwent repeat assessment of cardiorespiratory fitness and BMI at 1 and 4 years, there was a statistically significant association between improved fitness and lower risk of overall heart failure at 4 years (HR 0.86, 95\% CI 0.79-0.94). ${ }^{23}$

\section{More information needed on women and type of heart failure}

Other than in a study by Hu et $\mathrm{al},{ }^{21}$ which included comparable numbers of men $(1,921)$ and women $(1,693)$, women are vastly underrepresented in the studies. The Physicians' Health Study ${ }^{20}$ consisted entirely of men, and in the Cooper Center Longitudinal Study, ${ }^{19}$ women accounted for less than 10\% of participants in the overweight category and less than $11 \%$ in the obese category. Given the known differences between men and women, especially body fat distribution, more studies that include women are essential.

Another criticism is that only the Look AHEAD trial $^{23}$ determined the risk for specific heart failure phenotypes (ie, HFrEF vs $\mathrm{HFpEF}$ ). In most studies, the primary outcome was defined by a combination of International Classification of Diseases codes, limiting overall interpretation.

\section{Bottom line}

Despite limitations, these studies, taken as a whole, have two important implications for heart failure prevention:

- BMI and cardiorespiratory fitness both affect heart failure development, but fitness is likely the more significant factor

- Increased fitness is associated with a reduced risk of heart failure hospitalization as one ages. 


\section{TABLE 3}

\begin{tabular}{|c|c|c|c|c|c|}
\hline Study & $\mathrm{N}^{\mathrm{a}}$ & $\begin{array}{l}\text { Average LVEF of } \\
\text { target groups }\end{array}$ & Design $^{b}$ & End point & Main findings \\
\hline Lavie et $\mathrm{al}^{24}$ & 2,066 & $\begin{array}{l}\text { High fit }=30.1 \% \\
\text { Low fit }=26.0 \%\end{array}$ & $\begin{array}{l}\text { Patients stratified } \\
\text { by BMI and peak } \\
\mathrm{VO}_{2}\end{array}$ & $\begin{array}{l}\text { Overall } \\
\text { mortality }\end{array}$ & $\begin{array}{l}\text { In patients with low cardiorespiratory fitness, } \\
\mathrm{BMI} \geq 30 \mathrm{~kg} / \mathrm{m}^{2} \text { was a significant predictor of } \\
\text { better survival. No obesity paradox seen at } \\
\text { the high fitness level. }\end{array}$ \\
\hline Clark et al ${ }^{7}$ & 1,675 & $\begin{array}{l}\text { High fit }=23.4 \% \\
\text { Low fit }=23.2 \%\end{array}$ & $\begin{array}{l}\text { Patients stratified } \\
\text { by BMI and peak } \\
\mathrm{VO}_{2}\end{array}$ & $\begin{array}{l}\text { Death, urgent } \\
\text { status } 1 A \\
\text { heart trans- } \\
\text { plant, or VAD } \\
\text { placement. }\end{array}$ & $\begin{array}{l}\mathrm{BMI} \text { of obesity class was associated with a } \\
\text { significantly lower risk of death, urgent trans- } \\
\text { plant, or device placement than with normal } \\
\mathrm{BMI} \text { in the group with low peak } \mathrm{VO}_{2} \text {. In the } \\
\text { high peak } \mathrm{VO}_{2} \text { group, no difference was seen } \\
\text { for } \mathrm{BMI} \text { and survival. }\end{array}$ \\
\hline $\begin{array}{l}\text { Piepoli et } \\
\text { al27 MECKI } \\
\text { Score } \\
\text { Research } \\
\text { Group }\end{array}$ & 4,623 & $\begin{array}{l}\text { BMI }\left(\mathrm{kg} / \mathrm{m}^{2}\right) \\
<25=31 \% \\
25 \text { to } 30=33 \% \\
>30 \text { to } \leq 35=33 \% \\
>35=33 \%\end{array}$ & $\begin{array}{l}\text { Patients stratified } \\
\text { by BMI and peak } \\
\mathrm{VO}_{2}\end{array}$ & $\begin{array}{l}\text { All-cause } \\
\text { mortality and } \\
\text { CV death }\end{array}$ & $\begin{array}{l}\text { Higher } \mathrm{BMI} \text { and peak } \mathrm{Vo}_{2} \text { were significant } \\
\text { positive predictors of longer survival. When } \\
\text { patients in a } \mathrm{BMI} \text { category were matched } \\
\text { according to age, sex, } \mathrm{LVEF}_{\text {, and peak } \mathrm{VO}_{2} \text {, the }} \text { protective role of } \mathrm{BMI} \text { disappeared. }\end{array}$ \\
\hline $\begin{array}{l}\text { McAuley } \\
\text { et a }{ }^{26} \mathrm{FIT} \\
\text { Project }\end{array}$ & 774 & $\begin{array}{l}\text { High fit }=41 \% \\
\text { Low fit }=40 \%\end{array}$ & $\begin{array}{l}\text { Patients stratified } \\
\text { by BMI and peak } \\
\text { METs }\end{array}$ & $\begin{array}{l}\text { Overall } \\
\text { mortality }\end{array}$ & $\begin{array}{l}\text { Significant positive association between BMI } \\
\text { category and survival for exercise capacity } \\
<4 \text { METs, but not } \geq 4 \text { METs. }\end{array}$ \\
\hline
\end{tabular}

${ }^{\mathrm{a}}$ All patients had established heart failure.

${ }^{\mathrm{b}}$ All studies were retrospective.

$\mathrm{BMI}=$ body mass index; $\mathrm{CV}$ = cardiovascular; FIT = Henry Ford Exercise Testing; $\mathrm{LVEF}=$ left ventricular ejection fraction; MECKI = Metabolic Exercise test data combined with Cardiac and Kidney Indexes; METs = metabolic equivalents; $\mathrm{VAD}=$ ventricular assist device; $\mathrm{V}_{2}=$ exercise oxygen uptake

\section{HEART FAILURE PROGNOSIS: CARDIORESPIRATORY FITNESS AND BMI}

Studies have been conducted in patients with heart failure to determine the impacts of fitness and BMI, and whether fitness affects the obesity paradox (Table 3). $7,24-27$

Clark et $\mathrm{al}^{7}$ also found that higher fitness levels likely mitigate the obesity paradox in patients with heart failure. They assessed almost 2,000 patients referred for heart transplant evaluation. Participants were stratified by BMI and fitness, as determined by cardiopulmonary exercise testing. After 2 years of follow-up, a high BMI $\left(\geq 30 \mathrm{~kg} / \mathrm{m}^{2}\right)$ was a significant predictor of improved survival in the low-fitness group but not in the high-fitness group.

The Henry Ford Exercise Testing (FIT) Project ${ }^{26}$ followed nearly 800 participants with heart failure and a BMI of at least $18.5 \mathrm{~kg} / \mathrm{m}^{2}$. Participants were grouped into standard BMI categories and then stratified by fitness $(<4$ or $\geq 4$ METs) based on treadmill stress test- ing. After a mean follow-up of 10 years, the authors concluded that the higher the BMI, the lower the mortality in those with a low level of fitness, but not in those with a high level of fitness. Thus, exercise capacity should be considered when stratifying risk.

\section{HFrEF: Higher fitness may negate the obesity paradox}

In the MECKI Score Research Group study, ${ }^{27}$ 4,623 patients with HFrEF underwent maximum cardiopulmonary exercise testing at enrollment and were followed for a median of 3 years. The population was divided according to $\mathrm{BMI}$ and peak $\mathrm{VO}_{2}$. On univariate analysis, groups with higher BMI and peak $\mathrm{VO}_{2}$ had lower mortality. However, when groups were matched for age, sex, left ventricular ejection fraction (LVEF), and predicted peak $\mathrm{VO}_{2}$, the protective role of BMI disappeared.

\section{Fitness: An obesity paradox modifier}

The above studies support an obesity paradox- 
cardiorespiratory fitness dichotomy in established heart failure: obesity is predominantly protective in patients with low fitness but not in highly fit patients. Hence, high fitness can be thought of as a modifier of the obesity paradox.

A strength of the data is the wide range in the mean age of each low-fitness obese cohort (50.8-63 years), ${ }^{8,27}$ indicating that the protective effect of obesity is not limited to younger patients. Studies also have included a range of mean LVEF (23.6\%-40\%),2,7,27 suggesting that cardiorespiratory fitness is likely an obesity paradox modifier in patients with reduced LVEF (< 40\%), mid-range LVEF (40\%-50\%), and preserved LVEF (> 50\%).

\section{HFpEF: Does the obesity paradox hold?}

The obesity paradox is not as consistently reported for heart failure patients with preserved ejection fraction as it is for those with reduced ejection fraction. Aerobic exercise capacity has been examined in patients with preserved ejection fraction in relation to indices of obesity and adiposity. ${ }^{28,29}$ In those trials, BMI predicted lower exercise capacity but did not correlate with cardiac-specific functional and prognostic parameters, including measures of left ventricular function.

A retrospective analysis of the Treatment activity 1 to 3 times a month conferred a $26 \%$ decrease in new-onset heart failure development of Preserved Cardiac Function Heart Failure With an Aldosterone Antagonist (TOPCAT) trial $^{30}$ indicated that the obesity paradox may not hold for HFpEF. It found that a higher baseline level of physical activity was associated with lower risk of adverse cardiovascular events through the duration of the trial (median follow-up 2.4 years), independent of BMI and other risk factors.

It is possible that the apparent lack of an obesity paradox in HFpEF may be because obesity itself is a risk factor for HFpEF. Also, patients with $\mathrm{HFpEF}$ and obesity are more likely to have other cardiovascular risk factors such as hypertension, diabetes, and obstructive sleep apnea that may attenuate any protective effect of obesity. ${ }^{31}$

\section{What about heart failure with mid-range ejection fraction?}

Heart failure with mid-range ejection fraction (LVEF 40\%-50\%) is a more recently characterized group that is not well defined or understood. ${ }^{32,33}$ It is possible that the mechanisms underlying fitness as an obesity-paradox modifier in these patients are similar to those with reduced ejection fraction, but that is not well established. It is unclear if beneficial interventions in one group are relevant to the other.

\section{Obesity definitions vary by study}

Most of the above studies defined obesity broadly as a BMI greater than $30 \mathrm{~kg} / \mathrm{m}^{2}$, limiting the generalizability of conclusions. Only the MECKI Score study ${ }^{27}$ subdivided patients based on obesity classes. Certain BMI thresholds may exist for which protective effects of obesity become deleterious.

\section{IMPACT OF WEIGHT LOSS}

A meta-analysis by Mahajan et $\mathrm{al}^{4}$ found that weight loss induced by bariatric surgery resulted in significantly improved measures of cardiac function and morphology (diastolic function, left ventricular mass index, and left atrial size). However, clinical outcomes (eg, heart failure incidence) were not assessed. Furthermore, patients did not have a diagnosis of heart failure at baseline, so the effect of bariatric surgery in established heart failure was uncertain.

Other studies have not found improved cardiac function with weight loss. Kitzman et $\mathrm{al}^{34}$ found that left ventricular mass and relative wall thickness decreased after diet-induced weight loss, but resting cardiac function did not improve.

A Swedish registry study with nearly 40,000 participants without heart failure at baseline evaluated the effects of weight loss from either intensive lifestyle intervention or bariatric surgery. ${ }^{35}$ Baseline weight and BMI did not differ between the cohorts. Surgery led to $18.8 \mathrm{~kg}$ more weight loss than lifestyle interventions at 1 -year follow-up and $22.6 \mathrm{~kg}$ more at 2 years. After a median follow-up of 4.1 years, surgery was associated with lower heart failure incidence than lifestyle modification ( $4.1 \%$ vs $7.6 \%$ per 10,000 person-years; HR 0.54, 95\% CI 0.26-0.81). A $10-\mathrm{kg}$ weight loss from both cohorts combined resulted in decreased heart failure incidence (HR 0.77, 95\% CI 0.60-0.97).

Bariatric surgery may also help mitigate established heart failure. In a populationbased study, ${ }^{36} 524$ patients with heart failure were followed after bariatric surgery, with a 
composite of emergency department visits or hospitalizations for heart failure exacerbation as the primary outcome measure. In the 13 to 24 months after surgery, heart failure exacerbations were significantly reduced (odds ratio $0.57,95 \%$ CI 0.39-0.82). There were 184 heart failure events (43\% systolic and 57\% diastolic). No information on body weight reduction was reported, so it is unclear if more weight loss correlated with fewer events.

In contrast, a study by Zamora et $\mathrm{al}^{37}$ of 1,000 patients with ambulatory chronic HFrEF were followed for 3 years to determine the impact of significant weight loss (defined as more than $5 \%$ of body weight over 1 year) on the mortality rate. Mortality was higher in patients who lost significant weight $(27.6 \%)$ than in patients without significant weight loss $(15.3 \%)$. Among obese patients, significant weight loss was associated with a higher risk of all-cause death (adjusted HR 2.38, 95\% CI 1.31-4.32) than in nonobese patients (adjusted HR 1.83, 95\% CI 1.16-2.89).

\section{Does unintentional weight loss explain the obesity paradox?}

Intentional vs unintentional weight loss likely explains the different heart failure outcomes following weight loss, particularly in patients with HFrEF.

When evaluating candidates for intentional weight loss via bariatric surgery or lifestyle modifications, medical clearance for participation requires a certain level of baseline functional status. However, unintentional weight loss in patients with advanced HFrEF may be the result of sarcopenia and cardiac cachexia, leading to poor baseline metabolic reserves and adverse clinical outcomes. Thus, the obesity paradox may simply reflect the severity of heart failure, with lower BMI occurring in end-stage heart failure and obesity, indicating a better baseline metabolic reserve.

\section{Body composition is also important}

Patients with HFpEF and obesity also have sarcopenia and adipose infiltration of muscle, ${ }^{31}$ indicating a highly inflamed and catabolic state. This highlights one of the limitations of using BMI as a surrogate of adiposity, and it demonstrates the need to further describe body composition when evaluating heart failure outcomes.

More attention is being focused on the ef- fect of lean mass on cardiorespiratory fitness. Lean mass is used as a surrogate for skeletal muscle mass, which is independently associated with cardiorespiratory fitness, possibly via endothelial and mitochondrial dysfunction and respiratory muscle abnormalities. ${ }^{28,38}$ In a 2017 review, reduced lean mass contributed to impaired cardiorespiratory fitness, independent of cardiac function. ${ }^{39}$ BMI reductions occur with loss of lean mass, which may partially account for the obesity paradox in heart failure..$^{40}$

Osman et $\mathrm{al}^{41}$ prospectively studied 225 consecutive ambulatory patients with chronic systolic heart failure who were referred for cardiopulmonary exercise testing. They found that adjusting peak $\mathrm{VO}_{2}$ to lean mass provided greater prognostic strength than adjusting by body weight, particularly in people with obesity.

The pattern of regional tissue deposition, especially increased proportions of intra-abdominal fat, may play a key role in exercise intolerance in patients with HFpEF. Haykowsky et $\mathrm{al}^{42}$ found that patients with HFpEF had higher ratios of intermuscular fat to skeletal muscle mass than healthy controls, and this was significantly related to reduced peak $\mathrm{VO}_{2}$. This evidence suggests that body composition indices such as lean mass play an important role in cardiorespiratory fitness regardless of BMI.

\section{Drug-induced weight loss: The evidence is unclear}

There is little evidence to demonstrate the safety and efficacy of pharmacologic weight loss in patients with heart failure. A recent post hoc analysis of the Functional Impact of GLP-1 (glucagon-like peptide-1) for Heart Failure Treatment (FIGHT) trial ${ }^{43}$ found that in patients with reduced ejection fraction, there was a treatment-related $4.1-1 \mathrm{~b}$ weight loss for liraglutide vs placebo $(95 \%$ CI -7.94 to $-0.25 ; P<.04)$, but no effect was found in worsening heart failure, making the clinical implications unclear. More research is needed to determine whether pharmacologic weight loss is an effective strategy to improve clinical outcomes in this patient population.

\section{WHAT TO ADVISE PATIENTS?}

Studies support 2 major themes:

- Obesity and low cardiorespiratory fitness are risk factors for the development of heart failure

\section{In patients with established heart failure, obesity is predominantly protective in patients with low fitness}


TABLE 4

\section{The obesity paradox: What we know and what we don't}

$\begin{array}{ll}\text { Setting } & \text { Established study findings } \\ \text { Patients } & \text { BMI appears to be protective } \\ \text { with heart } & \text { predominantly in patients with low } \\ \text { failure } & \text { fitness. }\end{array}$

Heart Improving cardiorespiratory fitness

failure may be more important for risk prevention reduction than lowering $\mathrm{BMI}$.

In patients with established diabetes, improved fitness may decrease the risk of developing HFpEF.

Increasing BMI and specific measures of adiposity correlate with increased risk of developing heart failure.

Even small amounts of physical activity decrease risk of developing heart failure.

Physical activity appears to have a dose-dependent effect on heart failure risk, with the lowest risk associated with highest frequency of physical activity.

Weight loss

\section{Current limitations}

Different obesity classes have not been specifically evaluated.

No separate evaluation of patients with either preserved or mid-range ejection fraction; they are largely grouped with reduced ejection fraction.

No differentiation between types or duration of physical activity.

Limited specificity of type of heart failure as end point (ie, HFpEF, HFmrEF, or HFrEF).

Women underrepresented.

\section{Research questions}

Is cardiorespiratory fitness an obesity paradox modifier in specific classes of obesity?

Is cardiorespiratory fitness an obesity paradox modifier in HFpEF and HFmrEF?

What type of physical activity leads to the lowest risk of heart failure development?

How do BMI and cardiorespiratory fitness (and interventions) affect development of different types of heart failure?

Are findings relevant for women?
Lack of clinical outcomes data after intentional weight loss for patients with heart failure and obesity.

Limited data on specific exercise training programs in heart failure outcomes or prevention.
How does medical vs surgical weight loss affect heart failure morbidity and mortality rates, particularly with newer medical therapies for obesity?

How does supervised exercise for patients with heart failure and obesity affect fitness, weight loss, and outcomes?

$\mathrm{BMI}=$ body mass index; $\mathrm{HFmrEF}=$ heart failure with mid-range ejection fraction; $\mathrm{HFpEF}=$ heart failure with preserved ejection fraction; $\mathrm{HFrEF}=$ heart failure with reduced ejection fraction

- Obesity in people with low fitness is protective for those with established heart failure.

How can clinicians use this knowledge to advise patients regarding weight loss and exercise training? The answer is unclear. The most recent American and European heart failure guidelines give only limited guidance on obesity management in patients with established heart failure. ${ }^{44,45}$ A 2018 position paper from the Heart Failure Association of the European Society of Cardiology advocates cardiopulmonary exercise testing only for assessing the risk of heart failure. ${ }^{46}$

\section{Bottom line: Advise to increase fitness and consider weight loss}

Although large-scale clinical trials are needed to better assess and define the risks and ben- 
efits of weight loss in patients with heart failure, particularly in those with reduced ejection fraction, recommending moderate weight loss may be appropriate. Lifestyle interventions aimed at weight loss and improving cardiorespiratory fitness - such as with a phase 2 (outpatient) cardiac rehabilitation programshould be considered, as studies suggest they reduce heart failure risk by improving fitness in patients with obesity and heart failure. And no data suggest harm.

For heart failure prevention, weight loss through dietary and lifestyle changes can be recommended, given that evidence shows a lower BMI predicts reduced risk of heart failure development. In patients with established heart failure and reduced ejection fraction, it appears that intentional weight loss through lifestyle modification or bariatric surgery may be beneficial, ${ }^{35}$ although unintentional weight loss appears to be detrimental. ${ }^{36}$ Thus, when advising weight loss to obese patients with heart failure, it is important to consider the individual's clinical profile.

\section{FUTURE DIRECTIONS FOR RESEARCH}

Understanding the overlapping impact of obesity and cardiorespiratory fitness in heart failure is important to identify gaps in evidence and assess future research directions (Table 4).

A high priority for future studies is to better evaluate the impact of obesity on different heart failure phenotypes. Distinct pathophysiologic differences exist between heart failure with reduced, mid-range, or preserved ejec- tion fraction, with each responding differently to therapeutic interventions. Grouping all patients with heart failure together in analyses may blur results. Current literature has consistent findings in reduced ejection fraction, but dedicated analyses of preserved and mid-range ejection fraction are needed.

Similarly, it is likely that there are certain BMI thresholds where the protective effects of obesity become deleterious, but different obesity classes are commonly considered together in studies. Future research should examine if fitness modifies the obesity paradox in heart failure when assessing individuals with class II (BMI $\left.35-39.9 \mathrm{~kg} / \mathrm{m}^{2}\right)$ or class III $\left(>40 \mathrm{~kg} / \mathrm{m}^{2}\right)$ obesity.

Other major gaps in evidence include the specific weight reduction interventions that result in better heart failure outcomes in patients with obesity. Metabolic surgery has been studied the most. How do pharmacological therapies compare? How do supervised exercise programs (particularly cardiac rehabilitation) impact risk in patients with established heart failure? Which is more important, weight loss or increased cardiorespiratory fitness? Future studies should assess relative risk reduction of specific exercise training combined with metabolic surgery or pharmacotherapy-induced weight loss in patients with heart failure.

\section{DISCLOSURES}

The authors report no relevant financial relationships which, in the context of their contributions, could be perceived as a potential conflict of interest.

\section{REFERENCES}

1. Elagizi A, Kachur S, Lavie CJ, et al. An overview and update on obesity and the obesity paradox in cardiovascular diseases. Prog Cardiovasc Dis 2018; 61(2):142-150. doi:10.1016/j.pcad.2018.07.003

2. Shah R, Gayat E, Januzzi JL Jr, et al; GREAT (Global Research on Acute Conditions Team Network. Body mass index and mortality in acutely decompensated heart failure across the world: a global obesity paradox. J Am Coll Cardiol 2014; 63(8):778-785. doi:10.1016/j.jacc.2013.09.072

3. Zhang J, Begley A, Jackson R, et al. Body mass index and all-cause mortality in heart failure patients with normal and reduced ventricular ejection fraction: a dose-response meta-analysis. Clin Res Cardiol 2019; 108(2):119-132. doi:10.1007/s00392-018-1302-7

4. Mahajan R, Stokes M, Elliott A, et al. Complex interaction of obesity, intentional weight loss and heart failure: a systematic review and meta-analysis. Heart 2020; 106(1):58-68. doi:10.1136/heartjnl-2019-314770

5. Powell-Wiley TM, Ngwa J, Kebede S, et al. Impact of body mass index on heart failure by race/ethnicity from the Get With the Guidelines-Heart Failure (GWTG-HF) registry. JACC Heart Fail 2018; 6(3):233-242. doi:10.1016/j.jchf.2017.11.011

6. Lavie C, Alpert MA, Arena R, Mehra MR, Milani RV, Ventura HO. Impact of obesity and the obesity paradox on prevalence and prognosis in heart failure. JACC Heart Fail 2013; 1(2):93-102. doi:10.1016/j.jchf.2013.01.006

7. Clark AL, Fonarow GC, Horwich TB. Impact of cardiorespiratory fitness on the obesity paradox in patients with systolic heart failure. Am J Cardiol 2015; 115(2):209-213. doi:10.1016/j.amjcard.2014.10.023

8. Van Iterson EH, Kim CH, Uithoven K, Olson TP. Obesity and hemoglobin content impact peak oxygen uptake in human heart failure. Eur J Prev Cardiol 2018; 25(18):1937-1946. doi:10.1177/2047487318802695

9. Poirier P, Giles TD, Bray GA, et al. Obesity and cardiovascular disease: pathophysiology, evaluation, and effect of weight loss: an update of the 1997 American Heart Association Scientific Statement on Obesity and Heart Disease from the Obesity Committee of the Council on Nutrition, Physical Activity, and Metabolism. Circulation 2006; 113(6):898-918. doi:10.1161/CIRCULATIONAHA.106.171016

10. Alpert MA, Lavie C, Agrawal H, Aggarwal KB, Kumar SA. Obesity and heart failure: epidemiology, pathophysiology, clinical manifestations, and management. Transl Res 2014; 164(4):345-356. doi:10.1016/j.trsl.2014.04.010

11. Kodama S, Saito K, Tanaka S, et al. Cardiorespiratory fitness as a quantitative predictor of all-cause mortality and cardiovascular events in healthy men and women: a meta-analysis. JAMA 2009; 301(19):2024-2035. doi:10.1001/jama.2009.681 
12. Kaminsky LA, Arena R, Ellingsen $\emptyset$, et al. Cardiorespiratory fitness and cardiovascular disease - the past, present, and future. Prog Cardiovasc Dis 2019; 62(2):86-93. doi:10.1016/j.pcad.2019.01.002

13. Blair SN, Kampert JB, Kohl HW 3rd, et al. Influences of cardiorespiratory fitness and other precursors on cardiovascular disease and all-cause mortality in men and women. JAMA 1996; 276(3):205-210. pmid: 866756

14. Wei M, Kampert JB, Barlow CE, et al. Relationship between low cardiorespiratory fitness and mortality in normal-weight, overweight, and obese men. JAMA 1999; 282(16):1547-1553. doi:10.1001/jama.282.16.1547

15. Liu K, Daviglus ML, Loria CM, et al. Healthy lifestyle through young adulthood and the presence of low cardiovascular disease risk profile in middle age: the Coronary Artery Risk Development in (Young) Adults (CARDIA) study. Circulation 2012; 125(8):996-1004.

doi:10.1161/CIRCULATIONAHA.111.060681

16. Arbab-Zadeh A, Dijk E, Prasad A, et al. Effect of aging and physical activity on left ventricular compliance. Circulation 2004; 110(13):1799-1805. doi:10.1161/01.CIR.0000142863.71285.74

17. Brinker SK, Pandey A, Ayers CR, et al. Association of cardiorespiratory fitness with left ventricular remodeling and diastolic function: the Cooper Center Longitudinal Study. JACC Heart Fail 2014; 2(3):238-246. doi:10.1016/j.jchf.2014.01.004

18. Miyachi M, Yazawa H, Furukawa M, et al. Exercise training alters left ventricular geometry and attenuates heart failure in dahl salt-sensitive hypertensive rats. Hypertension 2009; 53(4):701-707. doi:10.1161/HYPERTENSIONAHA.108.127290

19. Pandey A, Cornwell WK, 3rd, Willis B, et al. Body mass index and cardiorespiratory fitness in mid-life and risk of heart failure hospitalization in older age: findings from the Cooper Center Longitudinal Study. JACC Heart Fail 2017; 5(5):367-374. doi:10.1016/j.jchf.2016.12.021

20. Kenchaiah S, Sesso HD, Gaziano JM. Body mass index and vigorous physical activity and the risk of heart failure among men. Circulation 2009; 119(1):44-52. doi:10.1161/CIRCULATIONAHA.108.807289

21. Hu G, Jousilahti P, Antikainen R, Katzmarzyk PT, Tuomilehto J. Joint effects of physical activity, body mass index, waist circumference, and waist-tohip ratio on the risk of heart failure. Circulation 2010; 121(2):237-244. doi:10.1161/CIRCULATIONAHA.109.887893

22. Kokkinos $\mathbf{P}$, Faselis $\mathbf{C}$, Franklin $\mathbf{B}$, et al. Cardiorespiratory fitness, body mass index and heart failure incidence. Eur J Heart Fail 2019; 21(4):436-444. doi:10.1002/ejhf.1433

23. Pandey A, Patel KV, Bahnson JL, et al; Look AHEAD Research Group. Association of intensive lifestyle intervention, fitness, and body mass index with risk of heart failure in overweight or obese adults with type 2 diabetes mellitus: an analysis from the Look AHEAD trial. Circulation 2020; 141(16):1295-1306. doi:10.1161/CIRCULATIONAHA.119.044865

24. Lavie C, Cahalin LP, Chase P, et al. Impact of cardiorespiratory fitness on the obesity paradox in patients with heart failure. Mayo Clin Proc 2013; 88(3):251-258. doi:10.1016/j.mayocp.2012.11.020

25. Mancini DM, Eisen H, Kussmaul W, Mull R, Edmunds LH, Jr., Wilson JR. Value of peak exercise oxygen consumption for optimal timing of cardiac transplantation in ambulatory patients with heart failure. Circulation 1991; 83(3):778-786. doi:10.1161/01.cir.83.3.778

26. McAuley PA, Keteyian SJ, Brawner CA, et al. Exercise capacity and the obesity paradox in heart failure: the FIT (Henry Ford Exercise Testing) Project. Mayo Clin Proc 2018; 93(6):701-708. doi:10.1016/j.mayocp.2018.01.026

27. Piepoli MF, Corra U, Veglia F, et al; MECKI Score Research Group. Exercise tolerance can explain the obesity paradox in patients with systolic heart failure: data from the MECKI Score Research Group. Eur J Heart Fail 2016; 18(5):545-553. doi:10.1002/ejhf.534

28. Carbone S, Billingsley HE, Rodriguez-Miguelez P, et al. Lean mass abnormalities in heart failure: the role of sarcopenia, sarcopenic obesity, and cachexia. Curr Probl Cardiol 2020; 45(11):100417. doi:10.1016/j.cpcardiol.2019.03.006

29. Lavie C, Ozemek C, Carbone S, Katzmarzyk PT, Blair SN. Sedentary behavior, exercise, and cardiovascular health. Circ Res 2019; 124(5):799-815. doi:10.1161/CIRCRESAHA.118.312669

30. Hegde SM, Claggett B, Shah AM, et al. Physical activity and prognosis in the TOPCAT trial (Treatment of Preserved Cardiac Function Heart Failure With an Aldosterone Antagonist). Circulation 2017; 136(11):982-992. doi:10.1161/CIRCULATIONAHA.117.028002
31. Pandey A, Patel KV, Vaduganathan M, et al. Physical Activity, fitness, and obesity in heart failure with preserved ejection fraction. JACC Heart Fail 2018; 6(12):975-982. doi:10.1016/j.jchf.2018.09.006

32. Webb J, Draper J, Fovargue L, et al. Is heart failure with mid range ejection fraction (HFmrEF) a distinct clinical entity or an overlap group? Int J Cardiol Heart Vasc 2018; 21:1-6. doi:10.1016/j.ijcha.2018.06.001

33. Branca L, Sbolli M, Metra M, Fudim M. Heart failure with mid-range ejection fraction: pro and cons of the new classification of Heart Failure by European Society of Cardiology guidelines. ESC Heart Fail 2020; 7(2):381-399. doi:10.1002/ehf2.12586

34. Kitzman DW, Brubaker P, Morgan T, et al. Effect of caloric restriction or aerobic exercise training on peak oxygen consumption and quality of life in obese older patients with heart failure with preserved ejection fraction: a randomized clinical trial. JAMA 2016; 315(1):36-46. doi:10.1001/jama.2015.17346

35. Sundstrom J, Bruze G, Ottosson J, Marcus C, Naslund I, Neovius M. Weight loss and heart failure: a nationwide study of gastric bypass surgery versus intensive lifestyle treatment. Circulation 2017; 135(17):1577-1585. doi:10.1161/CIRCULATIONAHA.116.025629

36. Shimada YJ, Tsugawa Y, Brown DFM, Hasegawa K. Bariatric surgery and emergency department visits and hospitalizations for heart failure exacerbation: population-based, self-controlled series. J Am Coll Cardiol 2016; 67(8):895-903. doi:10.1016/j.jacc.2015.12.016

37. Zamora E, Diez-Lopez C, Lupon J, et al. Weight loss in obese patients with heart failure. J Am Heart Assoc 2016; 5(3):e002468. doi:10.1161/JAHA.115.002468

38. Kitzman DW, Nicklas B, Kraus WE, et al. Skeletal muscle abnormalities and exercise intolerance in older patients with heart failure and preserved ejection fraction. Am J Physiol Heart Circ Physiol 2014; 306(9):H1364-1370. doi:10.1152/ajpheart.00004.2014

39. Carbone S, Popovic D, Lavie C, Arena R. Obesity, body composition and cardiorespiratory fitness in heart failure with preserved ejection fraction. Future Cardiol 2017; 13(5):451-463. doi:10.2217/fca-2017-0023

40. Ventura HO, Carbone S, Lavie C. Muscling up to improve heart failure prognosis. Eur J Heart Fail 2018; 20(11):1588-1590. doi:10.1002/ejhf.1314

41. Osman AF, Mehra MR, Lavie CJ, Nunez E, Milani RV. The incremental prognostic importance of body fat adjusted peak oxygen consumption in chronic heart failure. J Am Coll Cardiol 2000; 36(7):2126-2131. doi:10.1016/s0735-1097(00)00985-2

42. Haykowsky MJ, Kouba EJ, Brubaker PH, Nicklas BJ, Eggebeen J, Kitzman DW. Skeletal muscle composition and its relation to exercise intolerance in older patients with heart failure and preserved ejection fraction. Am J Cardiol 2014; 113(7):1211-1216. doi:10.1016/j.amjcard.2013.12.031

43. Sharma A, Ambrosy AP, DeVore AD, et al. Liraglutide and weight loss among patients with advanced heart failure and a reduced ejection fraction: insights from the FIGHT trial. ESC Heart Fail 2018; 5(6):1035-1043. doi:10.1002/ehf2.12334

44. Writing Committee Members; Yancy CW, Jessup M, Bozkurt B, et al; American College of Cardiology Foundation/American Heart Association Task Force on Practice Guidelines. 2013 ACCF/AHA guideline for the management of heart failure: a report of the American College of Cardiology Foundation/American Heart Association Task Force on practice guidelines. Circulation 2013; 128(16):e240-e327. doi:10.1161/CIR.0b013e31829e8776

45. Ponikowski P, Voors AA, Anker SD, et al; Authors/Task Force Members; Document Reviewers. 2016 ESC Guidelines for the diagnosis and treatment of acute and chronic heart failure: The Task Force for the diagnosis and treatment of acute and chronic heart failure of the European Society of Cardiology (ESC). Developed with the special contribution of the Heart Failure Association (HFA) of the ESC. Eur J Heart Fail 2016; 18(8): 891-975. doi:10.1002/ejhf.592

46. Corra U, Agostoni PG, Anker SD, et al. Role of cardiopulmonary exercise testing in clinical stratification in heart failure. A position paper from the Committee on Exercise Physiology and Training of the Heart Failure Association of the European Society of Cardiology. Eur J Heart Fail 2018; 20(1):3-15. doi:10.1002/ejhf.979

Address: Luke J. Laffin, MD, Section of Preventive Cardiology and Rehabilitation, JB-1, Cleveland Clinic, 9500 Euclid Avenue, Cleveland, OH 44195; laffin/@ccf.org 